\title{
BMJ Open Do chronic heart failure symptoms interact with burden of treatment? Qualitative literature systematic review
}

\author{
Rosalynn C Austin (D) , 1,2,3 Lisette Schoonhoven (D) ,2,3,4 Mike Clancy (D) ,2,5 \\ Alison Richardson (D) , 2,3,5 Paul R Kalra (D) , ${ }^{1,6,7}$ Carl R May (D) ${ }^{8,9}$
}

To cite: Austin RC, Schoonhoven L, Clancy M, et al. Do chronic heart failure symptoms interact with burden of treatment? Qualitative literature systematic review. BMJ Open 2021;11:e047060. doi:10.1136/ bmjopen-2020-047060

- Prepublication history and additional online supplemental material for this paper are available online. To view these files, please visit the journal online (http://dx.doi.org/10. 1136/bmjopen-2020-047060)

Received 17 November 2020 Accepted 28 June 2021

Check for updates

(C) Author(s) (or their employer(s)) 2021. Re-use permitted under CC BY-NC. No commercial re-use. See rights and permissions. Published by BMJ.

For numbered affiliations see end of article.

Correspondence to

Rosalynn C Austin;

r.c.austin@soton.ac.uk

\section{ABSTRACT}

Objective Explore the interaction between patient experienced symptoms and burden of treatment (BoT) theory in chronic heart failure (CHF). BoT explains how dynamic patient workload (self-care) and their capacity (elements influencing capability), impacts on patients' experience of illness.

Design Review of qualitative research studies. Data sources CINAHL, EMBASE, MEDLINE, PsycINFO, Scopus and Web of Science were searched between January 2007 and 2020.

Eligibility Criteria Journal articles in English, reporting qualitative studies on lived experience of CHF.

Results 35 articles identified related to the lived experience of 720 patients with CHF. Symptoms with physical and emotional characteristics were identified with breathlessness, weakness, despair and anxiety most prevalent. Identifying symptoms' interaction with BoT framework identified three themes: (1) Symptoms appear to infrequently drive patients to engage in selfcare $(9.2 \%$ of codes), (2) symptoms appear to impede (70.5\% of codes) and (3) symptoms form barriers to selfcare engagement $(20.3 \%$ of codes). Symptoms increase illness workload, making completing tasks more difficult; simultaneously, symptoms alter a patient's capacity, through a reduction in their individual capabilities and willingness to access external resources (ie, hospitals) often with devasting impact on patients' lives.

Conclusions Symptoms appear to be integral in the patient experience of $\mathrm{CHF}$ and BoT, predominately acting to impede patients' efforts to engage in self-care. Symptoms alter illness workload, increasing complexity and hardship. Patients' capacity is reduced by symptoms, in what they can do and their willingness to ask for help. Symptoms can lower their perceived self-value and roles within society. Symptoms appear to erode a patient's agency, decreasing self-value and generalised physical deconditioning leading to affective paralysis towards self-care regimens. Together describing a state of overwhelming BoT which is thought to be a contributor to poor engagement in self-care and may provide new insights into the perceived poor adherence to self-care in the CHF population. PROSPERO registration number CRD42017077487.

\section{INTRODUCTION}

Chronic heart failure (CHF) is increasing in prevalence, it is now estimated there are just

\section{Strengths and limitations of this study}

- This is the first systematic literature review to explore the role of symptoms in burden of treatment in chronic heart failure (CHF).

- This is a review of previously published qualitative studies; observations are restricted by the choice of published quotes from the included articles, and our conclusions were formed by using data to develop explanatory ideas different from those of the original researchers.

- Difference in articles, like various healthcare settings, and broad patient characteristics strengthens the confidence that our observations are common in the CHF patient population.

- The innovative methods to visually illustrate the qualitative data, allows the reader to observe the depth and breadth of the themes outlined in the results.

- Examining existing qualitative literature with a different theoretical framework may form the foundation for an adaptation to burden of treatment theory with practical application to CHF service delivery.

under 1 million patients living with $\mathrm{CHF}$ in the UK. ${ }^{1}$ Despite major advances in its treatment, many people with $\mathrm{CHF}$ experience substantial symptom burden and life-limiting prognosis. ${ }^{2-4}$ The focus of CHF management is increasingly centred on self-care. ${ }^{5}$ This includes behavioural changes (limiting fluid intake, diet restrictions, physical activity); self-monitoring of physiological processes (weight gain, fluid retention, breathlessness, fatigue); management of multiple medications; and appropriate help-seeking in response to symptoms. These self-care activities form the core of patient workload or treatment burden. It has been suggested that poor adherence to self-care regimens contributes to delays in seeking help, hospital admissions, increasing treatments and costs, and poor patient outcomes. ${ }^{6}$ It should be noted, however, that experiences of illness and adherence to self-care regimens may be 
influenced by CHF symptoms or comorbidities, such as cognitive impairment, ${ }^{7}$ anaemia ${ }^{8}$ and fatigue. ${ }^{9}$

Understanding interactions between symptoms and treatment burden in CHF is an important question, which has yet to be explored. It has been proposed that as symptom burden increases, there is a reduction in the affective, cognitive, relational, informational, material and physical capacity of people with long-term conditions. This reduction in capacity is reflected in increases in experienced burden of treatment (BoT), the dynamic modifiable workload delegated to patients. ${ }^{10-12}$ BoT theory ${ }^{12}$ explains how patient workload (assigned illness tasks) and their capacity (elements influencing capability), impacts on the experience of illness; where overwhelming BoT leads to patient disengagement with self-care. ${ }^{10-16} \mathrm{BoT}$ theory was chosen as it provides a patient focused framework to explore CHF patient experience, focusing on patients' individual capacity, illness workload and their effects. We have previously argued ${ }^{17}$ that interactions between symptoms and treatment burden are important in $\mathrm{CHF}$ and in this qualitative literature review we identify, characterise and explain these interactions as they are reported in the literature, and explore their implications for understanding patient experience and self-care outcomes.

\section{Aim of review}

To undertake a systematic review of qualitative literature on the lived experiences of CHF to identify, characterise and explain interactions between symptoms and BoT using mixed-method content analysis using BoT theory as a framework for analysis.

\section{Research question}

Do symptoms in CHF interact with BoT?

\section{METHODS}

\section{Identification of studies}

Using a refined search strategy (adapted from May et al, ${ }^{15}$ we searched CINAHL, EMBASE, MEDLINE, PsycINFO, Scopus and Web of Science. Search strategies are provided (online supplemental material S1). Bibliographies of included articles and relevant review articles were hand searched. Worldwide English language primary qualitative research articles were examined for descriptions of living with, and managing, CHF from the patient perspective. Mixed-method studies were considered for inclusion but required a substantial focus on qualitative methods to be included. Patient experience of heart transplant, endof-life care, and CHF treatment effects were excluded. Searches were limited to articles published between January 2007 and 20 January 2020 (table 1).

\section{Study selection}

RA screened titles and abstracts, using Covidence, ${ }^{18}$ against eligibility criteria. MC, who was blinded to RA's decisions, reviewed a random selection of 357 articles.
Table 1 Eligibility criteria for included articles

\begin{tabular}{|c|c|}
\hline Inclusion criteria & Exclusion criteria \\
\hline $\begin{array}{l}\text { Participants: aged }>18 \text { years } \\
\text { old with a diagnosis of } \mathrm{CHF}\end{array}$ & $\begin{array}{l}\text { Experience of patients with } \\
\text { heart transplant or palliative } \\
\text { care related to CHF }\end{array}$ \\
\hline $\begin{array}{l}\text { Articles: Qualitative studies } \\
\text { of participants lived } \\
\text { experience of living with and } \\
\text { managing CHF, published } \\
\text { in peer-reviewed journals } \\
\text { or as part of successful } \\
\text { PhD thesis. Mixed-methods } \\
\text { studies will be considered } \\
\text { but must have a substantial } \\
\text { focus on qualitative methods }\end{array}$ & $\begin{array}{l}\text { Qualitative studies not } \\
\text { reporting on general or holistic } \\
\text { lived experience (eg, paper } \\
\text { with a singular focus). } \\
\text { Reports of intervention } \\
\text { effectiveness, for example, } \\
\text { where the focus is on } \\
\text { the treatment effect or } \\
\text { service delivery rather than } \\
\text { the patients experience } \\
\text { (randomised control trials, } \\
\text { healthcare organisation or } \\
\text { delivery) } \\
\text { Literature review papers } \\
\text { (including qualitative } \\
\text { synthesis, meta-synthesis, etc) }\end{array}$ \\
\hline
\end{tabular}

Settings: Worldwide

Date of publication: between

1 January 2007 and 20

January 2020

Language: English

$\mathrm{CHF}$, chronic heart failure.

Disagreements were resolved by CRM and LS. Full-text articles were retrieved, and a final decision regarding eligibility made. The comprehensiveness of the search was confirmed through hand searching articles bibliography.

\section{Article quality assessment}

RA, CRM and LS assessed articles using Critical Appraisal Skills Programme. ${ }^{19}$ Papers were scored on the presence of additional participant and CHF characteristics. Articles were grouped into high or medium quality categories. NVivo ${ }^{20}$ analysis demonstrated no theme was preferentially represented in either high or medium quality articles; therefore, all articles were considered equally.

\section{Data extraction and analysis}

Data from the findings/results sections, including published supplemental data, were extracted from each paper. Using the extracted data a mixed-method content analysis was performed which combines quantitative and qualitative content analysis methods. ${ }^{21}$

\section{Quantitative content analysis}

Descriptive characteristics of the articles and participants were extracted and where possible summarised using descriptive statistics. NVivo assigns the term node to a grouping of codes defined by the researcher. A code is a segment of text from included articles. NVivo creates automatic counts of how often a node was 
coded (frequency) and how many articles the node was present in (consistency). Custom NVivo queries were built to count when symptom nodes occurred within the a priori BoT framework which was developed by RA, CRM and LS (online supplemental material S2). Counts of symptom nodes were used to rank the symptoms according to the frequency and consistency of coding in included articles. Sankey diagrams were built using an open-source coding programme, SankeyMATIC. ${ }^{22}$ A Sankey diagram is a flow diagram, where the width of the arrows represents the depth of that interaction or flow rate.

\section{Qualitative analysis}

A refinement of Thomas and Harden ${ }^{23}$ methodology for thematic synthesis was used. Stage 1, identification: Extracted data were examined by RA for text referring to symptoms of CHF, forming symptom nodes. A patient and public involvement (PPI) group reviewed the symptom nodes, reorganising and refining the nodes, while simultaneously checking for errors and bias. This process was repeated by a Heart Failure Specialist Nurse (MG). Stage 2, characterisation: Codes in each symptom node were read in context and a descriptive theme created capturing the context associated with that symptom. The constant comparison method ${ }^{24}$ facilitated an in-depth exploration of the nature of any observed interactions. Stage 3, explain: Descriptive themes were systematically examined, compared with the BoT a priori framework coding. Simultaneously, how each symptom acted on the framework was also coded.

\section{Role of public and patient involvement}

PPI included the refinement of the research question, symptom nodes, and confirmed coding structure. PPI members reported that results presented in this paper related to their experiences.

\section{RESULTS}

\section{Results: quantitative content analysis}

Searches were first run on 4 November 2017 and repeated on 1 January 2020. This returned 7349 results, duplicates were removed leaving 4497 articles to be examined for eligibility, resulting in 35 articles to be included (figure 1). A full list of included articles is provided (online supplemental material S3). Table 2 presents a summative description of included articles.

These articles present the CHF patient experience from healthcare systems in 14 countries, primarily through interview techniques and represent the experience of 720 participants $(57.6 \%$ male). Symptoms were grouped by physical and emotional characteristics (figure 2). In this article we will refer to these groupings as physical and emotional symptoms. Breathlessness, weakness, and disturbed sleep were the three most prevalent physical symptoms; while despair, anxiety, and fear the most prevalent emotional symptoms.

Figure 3 illustrates how coded symptoms interacted with coded elements of BoT framework. The width of the connectors represents how frequently these codes interacted, acting as a visual representation of the prevalence of each type of interaction observed in the data. CHF symptoms appeared to drive $(9.2 \%$ of codes, $n=238)$, impede (70.5\% of codes, $\mathrm{n}=1823$ ) or form a barrier to patients' engagement with elements of BoT (20.3\% of codes, $\mathrm{n}=525)$. Suggesting that symptoms rarely encourage patients to engage with self-care. Predominantly, symptoms make selfcare more difficult and can stop patients from engaging with self-care.

\section{Results: qualitative content analysis}

Here interaction is defined as how a CHF symptom impacted on the patient, influencing their self-care engagement and concurrently altering BoT. Constant comparative analysis $^{25}$ revealed positive (drive) and negative (impede and barrier) interactions between symptoms and BoT. Each of these interactions are considered in turn in the following section. Drive was defined as an interaction where the presence of a symptom meant the patient then positively engaged with an element of their BoT (eg, attend hospital, take medications, etc...). Where Impede was defined as the symptoms making this engagement more difficult and Barrier was defined as symptoms stopping patient engagement in this work.

\section{Symptoms drive patients to engage with self-care}

Symptoms are generally accepted to be the impetus which causes an individual to seek healthcare advice, take medications, and make lifestyle changes. Symptoms appeared to drive patients to positively engage with: (1) workload in asking for help, and (2) workload in performing tasks of CHF self-care. Symptoms also encouraged patients to use their capacity to access external resources. Table 3 provides exemplar quotes and figure 3 illustrates the interactions.

Symptoms can encourage patients to engage in the tasks of CHF self-care; from seeking urgent help from healthcare services to adapting activities of daily living to limiting symptom exacerbation. ${ }^{26-50}$ Symptoms urged patients to access healthcare systems for treatment adjustments or hospital admissions, ${ }^{27} 2830333536384346-4951$ receive support from social networks, ${ }^{26} 27$ 29-32 $34353739-4345474952$ engage with self-care tasks ${ }^{26-29} 32364045-474950$ and make physical environments alterations. ${ }^{26} 293149$ Symptoms compelled patients to recruit help from their social networks. Family and friends assumed tasks without being asked, that were beyond patient capacity. They also provided emotional support to patients. Without help from friends and family patients felt managing their illness was more difficult.

Symptoms Impede patient engagement with self-care

Symptoms of CHF are acknowledged as burdensome, this type of interaction was coded impede, meaning symptoms 


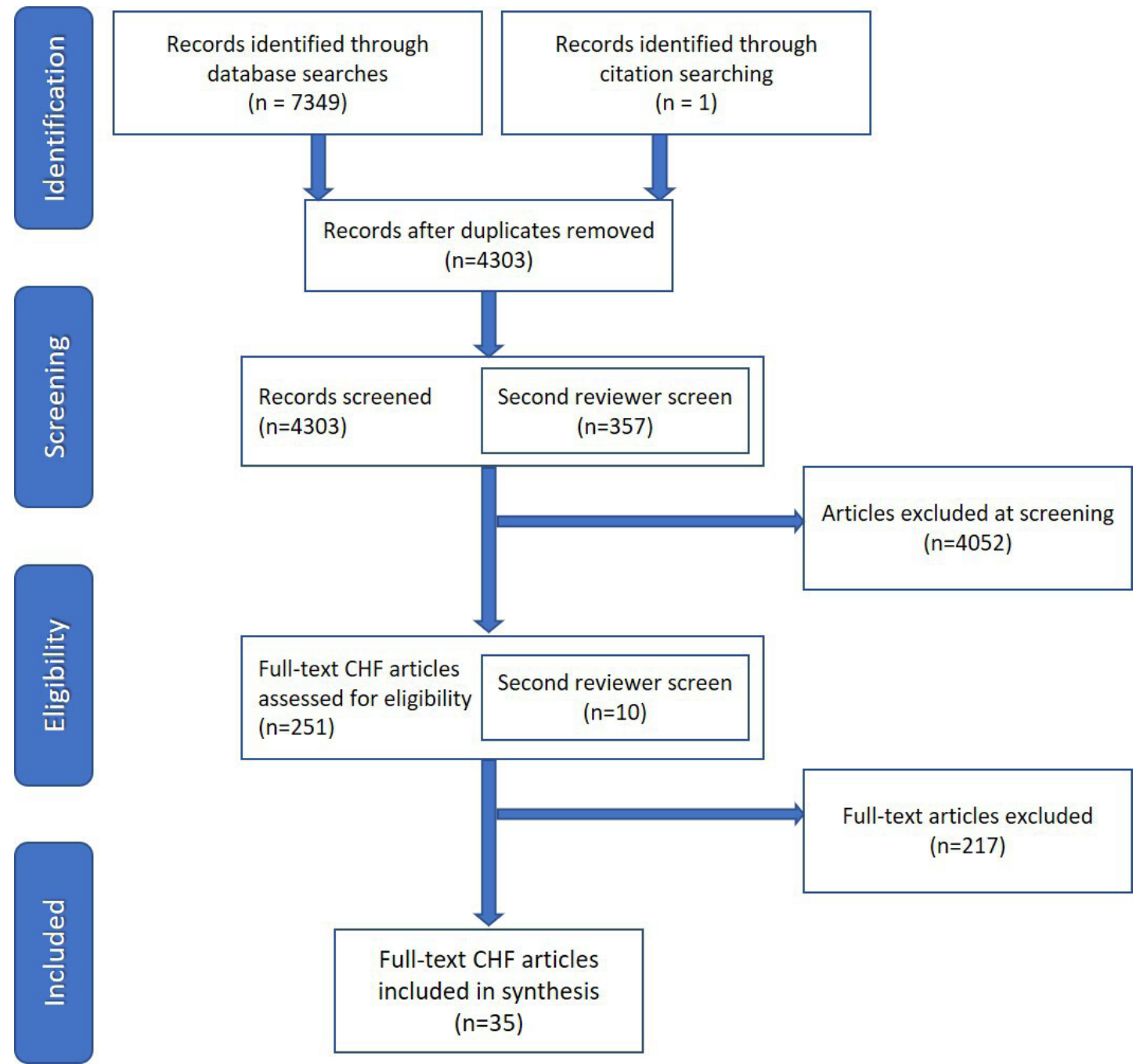

Figure 1 PRISMA flow chart for CHF articles on patient experience. CHF, chronic heart failure; PRISMA, Preferred Reporting Items for Systematic Reviews and Meta-Analyses.

made self-care more difficult. Symptoms appear to impede patients' ability to engage with their self-care. Symptoms appeared to hinder patients in the following areas: (1) workload in performing the tasks of CHF self-care, (2) workload in gaining knowledge of CHF, (3) capacity to utilise physical, emotional, mental and spiritual abilities, (4) capacity to access external resources and (5) impact of changes to patient self and role. Table 4 provides exemplar quotes and figure 3 illustrates the interactions.

Symptoms made monitoring and management of $\mathrm{CHF}$ harder. ${ }^{28-31}$ 35-38 404144464850515354 Completing specific tasks such as taking medications, attending appointments and other self-care activities become more difficult in the presence of symptoms. ${ }^{27} 2830$ 34-40 $444648-5153$ Further multiple comorbidities (common in CHF) can create confusion around which illness was responsible for what symptom and which treatment takes priority. ${ }^{28} 3335374041464753$

Symptoms made daily activities like housework, leisure activities, sexual intimacy and personal hygiene more difficult restricting patients' holistic participation in life. ${ }^{26} 2829313234-434649-51535556$ Within this context of impaired capability, engagement with lifestyle changes was limited. ${ }^{31} 36394043465153$ When CHF patients were unsuccessful in completing work assigned by healthcare practitioners: stress, guilt, and anxiety were exacerbated. ${ }^{28} 3740444850$ Some reported purposely choosing not to make lifestyle behaviour changes as the effort of these changes outweighed perceived benefits. ${ }^{46} 50$

Symptoms can restrict patients' ability to acquire knowledge around CHF. The sometimes progressive and vague nature of $\mathrm{CHF}$ symptoms together with the presence of comorbidities created confusion hindering baseline understanding of CHF. $26293035-3746-5054$ Treatments for CHF can have iatrogenic effects leading to confusion between disease progression or treatment side effects deterring the evaluation of treatment outcomes. ${ }^{28} 3035-384050$ Increased self-monitoring of symptoms intensified fear and awareness of life-limiting diagnosis. Being taught about CHF was reported by patients as creating fear and sadness. ${ }^{28} 3050$

Symptoms have a pervasive interaction on patients' physical, mental, emotional and spiritual capabilities, reducing capacity. The interaction between CHF symptoms and patients' physical capability makes activities from 
Table 2 (A, B): characteristics of included articles

Total

\begin{tabular}{|c|c|c|}
\hline \multicolumn{3}{|c|}{$\begin{array}{l}\text { A. Summarised article characteristics. (n) represents no o } \\
\text { papers with that characteristic }\end{array}$} \\
\hline \multirow[t]{4}{*}{ Location } & North America & 11 \\
\hline & Asia & 9 \\
\hline & Europe & 14 \\
\hline & Africa & 1 \\
\hline \multirow{9}{*}{$\begin{array}{l}\text { Methodological } \\
\text { approach }\end{array}$} & Qualitative approach & 16 \\
\hline & Phenomenology & 6 \\
\hline & Secondary analysis & 3 \\
\hline & Hermeneutic & 2 \\
\hline & Mixed methods & 1 \\
\hline & Constructivist & 2 \\
\hline & Anthropologic & 1 \\
\hline & Grounded theory & 2 \\
\hline & Patient narrative & 2 \\
\hline \multirow[t]{3}{*}{ Methods } & Interview & 30 \\
\hline & Focus group & 3 \\
\hline & Patient narrative & 2 \\
\hline \multirow{9}{*}{$\begin{array}{l}\text { Published } \\
\text { participant } \\
\text { characteristics }\end{array}$} & NYHA Class & 21 \\
\hline & Ejection Fraction & 9 \\
\hline & Aetiology of CHF & 8 \\
\hline & Comorbidities & 12 \\
\hline & Duration of illness & 18 \\
\hline & Employment status & 17 \\
\hline & Education level & 10 \\
\hline & Marital status & 21 \\
\hline & Ethnicity & 18 \\
\hline
\end{tabular}

(B) Summarised participant descriptives for included articles. (n) represented the no of participants.

\begin{tabular}{llc} 
Sample size & Total participants & 720 \\
& Male: n (\%) & $415(57.6)$ \\
& Female: n (\%) & $270(37.5)$ \\
\hline \multirow{2}{*}{ Age range (years) } & $22-90$ \\
CHF & NYHA I (n of participants) & $25^{*}$ \\
characteristics & NYHA II (n of participants) & $111^{*}$ \\
& NHYA III (n of participants) & $163^{*}$ \\
& NHYA IV (n of participants) & $62^{*}$ \\
& Ejection fraction range & $15 \%-64 \%$ \\
Marital status & Married & $186^{*}$ \\
& Divorced & $38^{*}$ \\
& Widow & $32^{*}$ \\
& Single & $61^{*}$ \\
Employment & Retired & $171^{*}$ \\
& Unemployed & $35^{*}$ \\
& Employed & $50^{*}$ \\
& Disabled & $27^{*}$ \\
\hline
\end{tabular}

Continued

\begin{tabular}{llr} 
Table 2 Continued & \\
\hline \multirow{2}{*}{ Education } & Total \\
& Less than 12 years & $92^{*}$ \\
& High school or equivalent & $106^{\star}$ \\
Ethnicity & Whitersity or higher & $76^{*}$ \\
& Black & $183^{*}$ \\
& Thai & $143^{*}$ \\
& Chinese & $50^{*}$ \\
& Malaysian & $40^{*}$ \\
& Indian & $13^{*}$ \\
& Hispanic & $15^{*}$ \\
& Other & $4^{*}$ \\
& & $4^{*}$
\end{tabular}

*Numbers presented are the sums of published data, characteristics were not consistently published across all articles.

$\mathrm{CHF}$, chronic heart failure; NYHA, New York Heart Association.

talking to exercising more difficult. ${ }^{26-32}$ 34-38 4041 45-47 50-58 Decreases in physical capability often requires patients to recruit others to help with physical tasks, shifting the burden from physical onto emotional through reduced independence. $^{26-32} 3436-38404243454750-565960$ The co-ordination and recruitment of this assistance also increases demand on mental capabilities, with negative affects. We observed reported difficulties in comprehending information, decision making, forgetfulness and psychological distress. ${ }^{28} 3031$ 36-38 $4041454750-52$ Emotional capability appears affected by symptoms in four main ways: (1) physical symptoms directly causing emotional distress, ${ }^{28-30} 32 \quad 34 \quad 384045 \quad 4750-53 \quad 55 \quad 56 \quad 60 \quad$ (2) emotional distress due to being reliant on others to do their work, ${ }^{26} 29343841424555$ (3) a grief process around loss of abilities, ${ }^{28-31} 34363740424550-5559$ and (4) accepting a lifelimiting diagnosis. ${ }^{27} 28$ 30-32 3436374051525559 Symptoms mean patients lose what was and begrudgingly accept a new normal.

Symptoms appear to impede a patient's willingness to access capacity building external resources, such as, social support networks and healthcare systems. Patients' ability to access their social networks is hindered by creating emotional distress and a lack of belonging ${ }^{263140454650-5259}$; yet, symptoms require reliance on family or friends due to decreased physical capability. ${ }^{29} 32343541454950535560$ There was also a sense that physical limitations meant adapting or giving up recreational and social activities leading to isolation and loneliness. ${ }^{28} 304050515359$ Interactions with healthcare systems, around symptoms, were reported to cause fatigue, fear, confusion and depression. ${ }^{28} 30365053$ The ambiguous nature of CHF symptoms saw healthcare professionals sometimes mis-diagnose patients'; providing patients with wrong information, adding further confusion and harming relationship's 


\begin{tabular}{|c|c|c|c|}
\hline \multicolumn{2}{|c|}{ Physical Symptoms } & \multicolumn{2}{|c|}{ Emotional Symptoms } \\
\hline I was becoming more & & "I became very depressed" 60 & $\begin{array}{l}\text { "The absolute worst is our } \\
\text { anxiety and agony." } 31\end{array}$ \\
\hline $\begin{array}{l}\text { Breathlessness } \\
240 \text { mentions in } 33 \text { articles }\end{array}$ & & 117 mentions in 31 articles & $\begin{array}{r}\text { Anxiety } \\
129 \text { mentions in } 29 \text { articles }\end{array}$ \\
\hline 'Participants described & ions in 34 articles & $\begin{array}{l}\text { am scared I may } \mathrm{E} \\
\text { hospitalised" } 40\end{array}$ & $\begin{array}{l}\text { "I just feel that I need } \\
\text { somebody with me" } 35\end{array}$ \\
\hline difficulties in sleeping" 51 & $\begin{array}{l}\text { "you feel your mind not as } \\
\text { strong as it should be" } 34\end{array}$ & 106 mentions in 25 articles & $\begin{array}{l}\text { Loss of Independence } \\
68 \text { mentions in } 24 \text { articles }\end{array}$ \\
\hline 100 mentions in 26 articles & $\begin{array}{l}\text { ognitive Impairment } \\
0 \text { mentions in } 23 \text { articles }\end{array}$ & $\begin{array}{l}\text { "Frustration was also commonly } \\
\text { reported but this was usually in } \\
\text { relation to the limitations" } 56\end{array}$ & 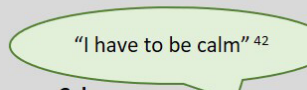 \\
\hline regs swent & $\begin{array}{l}\text { "many medications, often } \\
\text { with troublesome }\end{array}$ & Frustration $Z$ & 13 mentions in 17 articles \\
\hline 58 mentions in 24 articles & $\underbrace{\text { advers }}_{T}$ & & $\begin{array}{l}\text { "There was also a feeling of } \\
\text { isolation and loneliness" } 29\end{array}$ \\
\hline $\begin{array}{l}\text { But my heart a } \\
\text { chest never hurt }\end{array}$ & & & $\begin{array}{l}\text { I solation } \\
28 \text { mentions in } 9 \text { articles }\end{array}$ \\
\hline $\begin{array}{r}\text { Cardiac } \\
40 \text { mentions in } 19 \text { articles }\end{array}$ & and absolute tiredness ${ }^{45}$ & 18 mentions in 12 articles & "this life-threatening \\
\hline $\begin{array}{l}\text { "You feel those stings } \\
\text { and it upsets you" 5o }\end{array}$ & $\begin{array}{r}\text { Low energy } \\
120 \text { mentions in } 15 \text { articles }\end{array}$ & $\begin{array}{l}\text { "they felt guilty toward themselves } \\
\text { as well as feeling that they had let }\end{array}$ & $\begin{array}{l}\text { their loved ones reassess } \\
\text { their value to each other" } 53\end{array}$ \\
\hline Pain & $\begin{array}{l}\text { "heart failure exacerbations } \\
\text { from consuming extra }\end{array}$ & Guilt & 17 mentions in 7 articles \\
\hline "I also cannot drink, I & $\begin{array}{l}\text { liquids to treat a urinary } \\
\text { tract infection" } 37\end{array}$ & $\frac{16 \text { mentions in } 8 \text { artic }}{\text { "I am hoping to get }}$ & $\begin{array}{l}\text { "It feels good and positive when } \\
\text { you see yourself in a normal }\end{array}$ \\
\hline cannot eat." ${ }^{26}$ & Infection & & g fres \\
\hline $\begin{array}{r}\text { Poor appetite } \\
9 \text { mentions in } 8 \text { articles }\end{array}$ & 5 mentions in 4 articles & 9 mentions in 6 articles & $\begin{array}{r}\text { Happiness } \\
9 \text { mentions in } 6 \text { articles }\end{array}$ \\
\hline
\end{tabular}

Figure 2 Symptom terms found in included articles: name of symptom node in bold font with example quote in speech bubble. Counts of frequency consistency of coding are provided. HF, heart failure.

with healthcare professionals. ${ }^{33} 3647$ Healthcare systems were described as costly in terms of energy. ${ }^{28} 3050$

Symptoms negatively impacted financial resources draining family finances due to associated healthcare

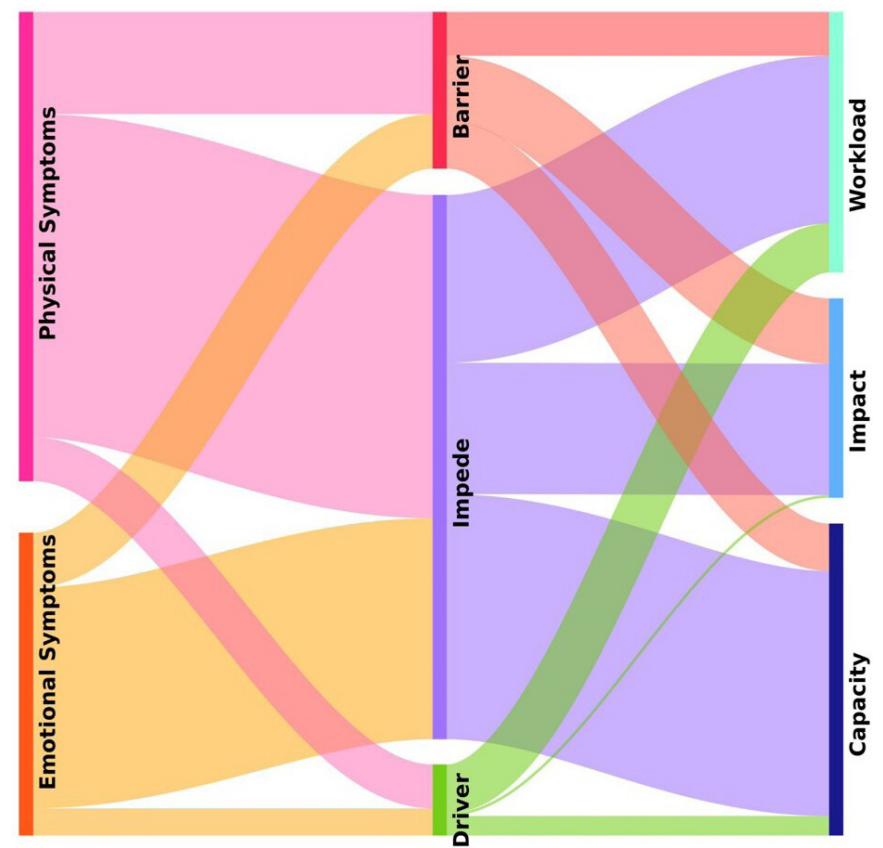

Figure 3 Sankey diagram of symptoms and the type of interaction they have with burden of treatment. Thickness of the flow bars represents the frequency of that interaction being coded in the analysis. costs, a finding observed in articles from Japan, Iran, Kenya, USA, Pakistan, Italy, UK, Sweden and Thailand. ${ }^{26} 2830364042465253$ Symptoms also alter a patient's employability decreasing family incomes and changing family roles. 262830364042465253 Unaffordable healthcare and treatments meant that symptoms were ignored by patients until the symptoms were unbearable or that their lives were threatened. ${ }^{26} 283040$

Symptoms impact on an individual's capabilities, altering their role within social networks, through a reduction in performing desired activities. The lack of ability to engage in tasks like housework or baking may seem trivial, but patients experience grief, frustration, anxiety at these changes. ${ }^{26} 28$ 29 31-36 38-42 $454649-5659$ If those alterations are central to their identity, then the impact of symptoms may extend to their perceived role in their social networks. Symptoms can strip the ability to provide for family, care for children and/or accepting the possibility of an early death. ${ }^{26}$ 28-31 35-38 40 42-47 49-53 555660 CHF treatments and self-care regimens designed to help patients were often recorded as disruptions thwarting patients' engagement in their self-care or causing further negative impact on

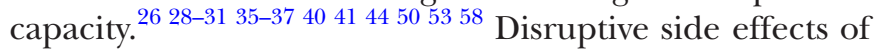
medication meant medications were not taken and/or social activities were restricted. ${ }^{28} 35-374050$

Symptoms create a barrier to patient engagement with self-care Finally, the presence of CHF symptoms appears to form a barrier to patients doing the work of illness. Symptoms 


\begin{tabular}{|c|c|}
\hline Construct & Themes with exemplar quotes \\
\hline Workload & 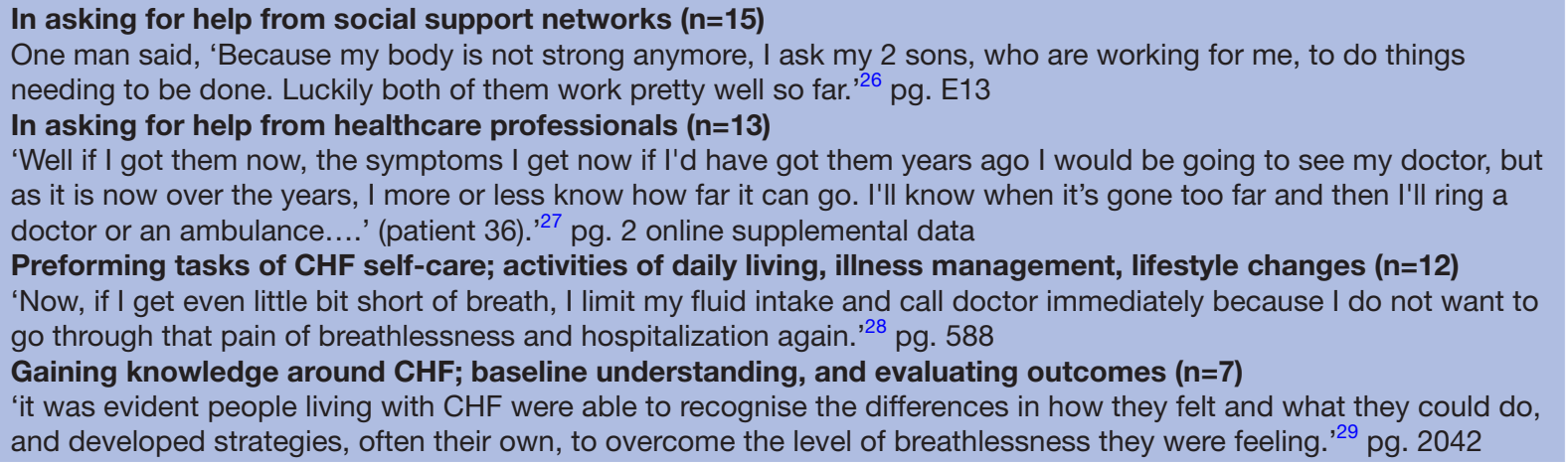 \\
\hline Capacity & $\begin{array}{l}\text { To utilize individual capacity; physical, mental, emotional, spiritual }(\mathbf{n}=\mathbf{8}) \\
\text { '... acute onset breathlessness caused significant anxiety and triggered a decision to seek emergency care. }{ }^{30} \mathrm{pg} .3 \\
\text { To utilize external resources; healthcare system, support networks, financial resources, physical environment } \\
(\mathbf{n}=\mathbf{1 5}) \\
\text { 'The patients provided different portrayals on aspects that facilitated living in their home despite physical changes. For } \\
\text { instance, to have the bedroom close by to the toilet was of importance since the symptoms of the disease might result } \\
\text { in rapid access to toilets. }{ }^{, 31} \mathrm{pg} .197\end{array}$ \\
\hline
\end{tabular}

Exemplar quotes illustrating how symptoms drive patients to engage with various elements of self-care connected to bot framework. ' $\mathrm{N}$ ' is number of articles coded to this theme in the BoT framework and had an interaction with a symptom of CHF. $\mathrm{CHF}$, chronic heart failure.

appeared to hinder patients in the following areas: (1) workload in performing tasks of CHF management, (2) workload in gaining knowledge of CHF syndrome, (3) capacity to use physical, emotional, mental and spiritual abilities, (3) individual capacity to access external resources, and (4) impact of changes to self and role. Table 5 provides exemplar quotes and figure 3 illustrates the interactions.

Symptoms can stop patients from engaging in the work of illness, from daily tasks to specific illness management tasks. Persistent and severe symptoms turn simple tasks into impossible ones. ${ }^{26-30} 33-38$ 40-42 44-46 48 50-54 565960 Assigned complex CHF self-care regimens likely become insurmountable in the face of such symptoms. 273842505159 The subjective nature of CHF symptoms can form a barrier to both patients and healthcare providers acting in a timely matter to those symptoms. ${ }^{30} 3335373841485459$ Resulting in delayed treatment seeking and poor illness management. 30333538454851

Symptoms of CHF appear to form a barrier to patients' physical, mental, emotional and spiritual abilities. $^{27} 293132363740-42455052-55575960$ The limitation in abilities creates a substantial deficit in their individual capacity, appearing to erode agency immobilising patients, who then suffer with CHF rather than living with it. $29323740-4245505560$

Symptoms also create a barrier to patients' accessing external resources. When symptoms were not correctly considered or interpreted by the healthcare professionals leading to negative feelings and mistrust from patients. ${ }^{3035} 384547$ Symptoms stop patients accessing their social support networks; they retreat from their social support networks fearing embarrassment and becoming burdensome. ${ }^{2628304042455052535560}$

Symptoms inhibit patients from performing desired activities, creating a sense of personal worthlessness. ${ }^{26} 293032363740-42454650-52545558-60$ The lack of individual capability alters their role in social support networks, forming a barrier to patients' relationships and future lives. ${ }^{26} 28-30323336374042454649-53555659$ The loss of perceived roles in social support networks has high cost. The power of the metaphors (see figure 4) used in patients' description of this interaction demonstrates the high degree of impact of symptoms on patient identity.

\section{DISCUSSION}

\section{Statement of findings}

Across the key domains of BoT (capacity, workload and impact) a complex interaction with symptoms was found; rarely driving patients to engage with self-care. We observed that CHF symptoms are intrinsic patients' description of CHF experience, altering BoT; adding to the understanding of factors which influence BoT in chronic illness. ${ }^{15}$ The work of treatment burden by Jani $e t$ $a f^{61}$ outlined the areas in CHF, in which symptoms likely play a role (eg, evaluation of treatments based on symptom monitoring). Previous work aligns with our finding that physical symptoms and their emotional affect may have a substantial influence on those with CHF limiting their physical and social capabilities and impacting on their psychological well-being align. ${ }^{62-65}$

Symptoms as a driver to engagement with self-care were seen in the minority $(<10 \%)$ of coded interactions with 
Table 4 Symptoms as impede patients in engaging with self-care

\section{Construct Themes with exemplar quotes}

Workload Preforming tasks of CHF self-care $(\mathrm{N}=31)$ :

Activities of daily living ( $n=20)$ : 'I can be just sitting, watching TV. And all of a sudden I get to breathing hard, you know. ${ }^{36}$ pg. 1632

Specific illness management tasks $(n=23)$ : 'I tried to walk up the health centre Monday before last...it must have taken an hour and 15 minutes to get back home...it's only a 10 minute walk. It's uphill and every couple of minutes I was sitting like a poor wino, with my feet in the road, sitting on the footpath to get my breath back and rested. (patient 18 , male, aged 69$)^{, 53}$ pg. 275

Lifestyle changes $(n=7)$ : 'Although the patients were aware of the need to modify their life-style, they believed that stress was worse and that it would be better to reduce stress by eating what they liked. ${ }^{46} \mathrm{pg} .4$

Gaining knowledge around CHF; baseline understanding, and evaluating outcomes $(\mathbf{n}=\mathbf{2 1})$

'I thought the signs were related to my prostate or lung problem, I never thought it was my heart. ${ }^{, 38}$ pg. 3602

In asking for help from social support networks or healthcare professional $(n=15)$

'The informants sometimes felt that other people did not understand or believe them when they said they were seriously ill. As signs of disease often are invisible in conditions of CHF. ${ }^{, 52}$ pg. 7

Capacity To utilize individual abilities $(\mathbf{n}=29)$ :

Physical ( $n=27)$ : 'I liked my garden and I used to come out and potter. I can't do that now...' (P7),34 pg. 266

Emotional $(n=25)$ : 'some very dark days over the years" and that much of the depression was caused by physical limitations. ${ }^{32}$ pg. 99

Mental ( $n=13)$ : 'About a quarter of the participants were experiencing cognitive impairments such as memory loss and concentration impairment. A 41year-old woman said: 'I need to read something several times to comprehend the material' (p13, higher education). ${ }^{, 40}$ pg. 826

Spiritual $(n=7)$ : 'I went down to Mass then in the car and I-my wife said to me 'You shouldn't go down because you're not able to walk all that far' and I really couldn't walk from the car park-I attempted and failed....and I'd only gone a few yards and I said 'Look I can't-you're right I can't go any further - I'll have to stop' - so I had to come back and get into the car and go home' (PI, p4) (Field Notes: Eyes filled with tears and voice became shaky) ${ }^{, 45}$ pg. 227

To utilize external resources $(n=24)$

Support networks $(n=20)$ : 'Due to my illness, there are so many things I can't be a part of anymore. I can't do so many things at a time, and I need plenty of time to do everything. (P14, NYHA III),50 pg. 1787

Healthcare system $(n=9)$ : 'To see a doctor, you have to wait for an hour. This is very tiring. ${ }^{\text {,2 }}$ pg. 588

Financial resources ( $n=9)$ : 'a 68-year-old male patient in NYHA class II reported 'I had to stop my job and I feel this has impacted negatively on me and my family life because I feel useless and now we have to live with only one salary." 42 pg. 266

Physical environment $(n=9)$ : 'As she spoke, she pointed to her environment-a three - levelled townhouse. She describe how she sometimes needed to sit on the stairs on the way up to her bedroom, she couldn't get downstairs to do her laundry and she couldn't go for walks because of snow on the sidewalks as she feared falling and not being able to get up. She talked about her shortness of breath, and how she 'slept' fearfully on the stairway. ${ }^{41} \mathrm{pg} .10$

\begin{tabular}{|c|c|}
\hline Impact & 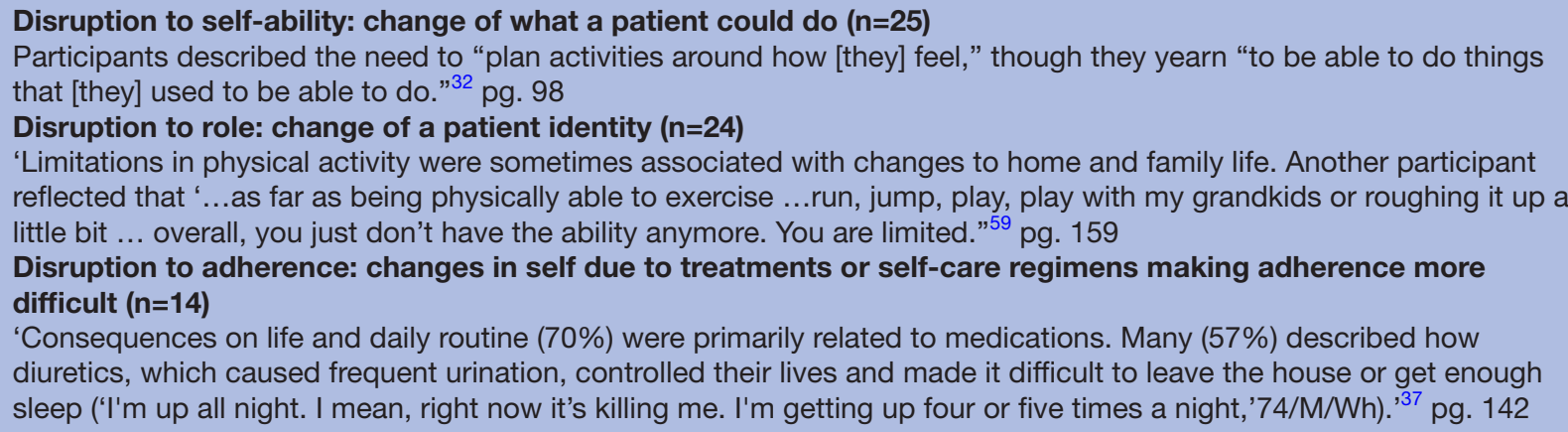 \\
\hline
\end{tabular}

Exemplar quotes illustrate how symptoms hindered patients' engagement with various elements of self-care connected to the bot framework. ' $\mathrm{N}$ ' is number of articles coded to this theme in the bot framework and had an interaction with a symptom of CHF. $\mathrm{CHF}$, chronic heart failure.

our BoT framework. This was unexpected as it is generally assumed that symptoms are the impetus for patients to engage with self-care. This finding, has parallels to the body of work relating to CHF patients' delaying in seeking healthcare support due to multiple influencing factors (eg, previous negative experiences, perceived barriers to care, misattribution of symptoms, etc ${ }^{66}$ rather than symptoms alone. ${ }^{67}$ Failures in self-care were previously blamed on a patients' denial of illness or poor health literacy ${ }^{63} 68$ rather than as this work suggests symptoms having a more complex interaction with patient engagement with healthcare services.

Symptoms impede engagement with self-care was coded in $70.5 \%$ interactions within our BoT framework. The work of managing CHF was made more difficult not only in increasing task difficulty due to decreased capacity, but 
Table 5 Symptoms as a barrier to patients in engaging with self-care

\section{Construct Themes with exemplar quotes}

Workload Preforming tasks of CHF self-care $(n=20)$ :

Activities of daily living ( $n=12)$ : 'Tired, tired, tired, when I sit and watch TV my eyes just fall down.... ${ }^{54} \mathrm{pg} .634$

Specific illness management tasks ( $n=11$ ): 'The treatment regimen is so complex I cannot figure it all out myself. I do not have the energy or the ability to manage it all. (P 6 NYHA II) $)^{50}$ pg. 1787

Gaining knowledge around CHF; understand illness and evaluating outcomes $(n=9)$

'For instance, one participant readily described having heart failure symptoms of fatigue and shortness-of-breath that he attributed to problems with his back, stating 'my heart is just fine.'79/M/Mix'37 pg. 138

In asking for help from social support networks or healthcare professional $(n=7)$

'I don't try for it [help], I'm too tired. I mean if anything went wrong I used to ring and shout and do something until they did it. Now I just sit back and wait. All the fight's gone out of me...I'm tired, I'm tired of fighting the world. (86-year-old female; NYHA III),51 pg. 77

Capacity To utilize individual abilities $(n=18)$ :

Physical ( $n=16$ ): "My friends have invited me over to France a couple of times and l've said that I couldn't manage it, getting in a car, driving over and driving back again. I've said I just can't do it.' P9. ${ }^{.55}$ pg.195

Emotional ( $n=6)$ : "It affected me emotionally, I became very depressed, I had bouts of depression. At one time I sort of gave up on life... one of the common emotion is frustration. I used to be able to do this thing you know, I used to be able to go out, to handle such situations; now I cannot.' (57 years, male, Chinese, married, FG3)'60 pg.94

Mental $(n=3)$ : 'Decision-making problems lead to impairment in self-care, failure in the timely reporting of the symptoms of disease severity, disability, frequent hospitalisation, decreased QOL and increased mortality rate, which indicates the importance of evaluating cognitive impairment in patients with $\mathrm{HF}^{4}{ }^{40}$ pg.827

Spiritual $(n=2)$ : 'The discipline and practice of Islam was mentioned in relation to knowledge and understanding about diet, exercise and general health... an inability to conduct ritual ablutions before daily prayers proved to be distressing for some patients, as did not being able to prostrate during prayer. ${ }^{.53} \mathrm{pg} .277$

To utilize external resources $(n=14)$

Support networks $(n=11)$

'A 62-year-old woman in NYHA class II reported 'I have friends but I can't go on holiday with them anymore. They recently went on holiday for 8-10 days and invited me, but I couldn't go because I feel tired and walking is more and more difficult for me. ${ }^{42}$ pg. 267

Healthcare system $(n=5)$

'However, some respondents were less positive about primary care professionals. A number of respondents reported an apparent delay in diagnosis by their GP, which had negative effects on their relationship. 'That was while the doctors were saying chest infections... so they weren't spotting the fluid.' KP5 'Oh it's your asthma, here....he didn't even examine me....it's only when my legs started, my ankles started swelling and we insisted.' KP4 ${ }^{35}$ pg.5

Impact Disruption to self-ability: change of what a patient could do $(\mathbf{n}=19)$
'Since I've had my heart problems I just feel so tired all the time and it's just made me so depressed. And I can't
do the things that I used to do, and I know I've gotten up in age, but ... I just feel like I should be able to do more
than what I'm doing now at $65.59 \mathrm{pg}$. 159
Disruption to role: change of a patient identity ( $\mathbf{n = 1 9}$ )
'Because my status was very serious when I was first diagnosed, my husband and I ... were advised to no longer
$\ldots$ try to become pregnant. My heart was too weak to go through childbirth. I was sad, but I understood. It wasn't
fair to bring a child into the world with ... such a very sick mommy ... Being a childless mother is a fallout of my
CHF.' pg. $98^{32}$

Exemplar quotes illustrate how symptoms stopped patients' engagement with various elements of self-care connected to the bot framework. ' $\mathrm{N}$ ' is number of articles coded to this theme in the bot framework and had an interaction with a symptom of CHF.

$\mathrm{CHF}$, chronic heart failure.

also through how symptoms are considered by healthcare professionals. The work of Lippiett $e t a l^{11}$ described how different patient clinical pathways influenced BoT in chronic obstructive pulmonary disease (COPD) and lung cancer, where lung cancer patients are expected to follow a structure treatment pathway meant less BoT. Where patients with COPD are expected to be engaged with self-care meant greater BoT. Deficits in CHF healthcare service delivery has previously been observed to make the work of self-care more difficult. ${ }^{65}{ }^{69}$ The high prevalence of this type of interaction within the framework suggests an intrinsic relationship with symptoms. Thus, emphasising importance of considering symptoms as more than an indicator for disease progression or treatment effectiveness, by healthcare professionals when assigning selfcare work to patients. Adding to the work of Gonçalves $e t$ $a l,{ }^{70}$ which identified a negative influence between BoT and the pathophysiology of illness across multiple health conditions. 


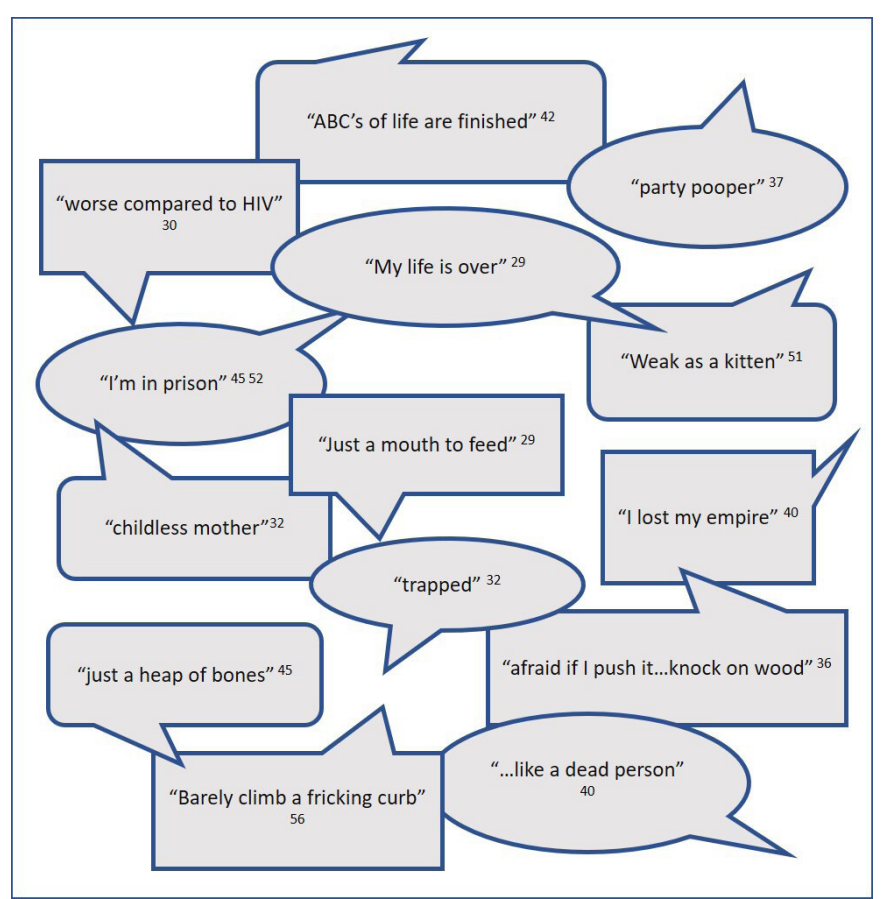

Figure 4 Exemplar metaphors used in description of how symptoms form barriers to engagement in desired activities and their perceived role.

Symptoms as a barrier to engagement with self-care was coded in $20.3 \%$ of the interactions within our BoT framework. If CHF symptoms removed patients' capacity, an unsurmountable illness workload can be created. Similarly, Yu et al, ${ }^{64}$ reported in older adults with CHF the work around symptom monitoring contributed to patients' physical and mental exhaustion; meaning poor self-care or reliance on social support systems. The high workload of CHF patients is similar to the exhausting and invasive BoT that Roberti et $a l^{71}$ noted in chronic kidney disease. From a patient perspective, symptoms strip their capacity and increase their workload creating overwhelming BoT. For them the effort of attempting to do the work assigned by healthcare professionals is not worth the physical effort or emotional stress as perceived benefits are so low. This affectively inhibits patients from engaging in self-care. Previous reviews on living with heart failure appear to neglect highlighting the importance of symptoms on capacity to do this work instead focusing on patients' poor adaptation to their illness and its impact on their lives ${ }^{68}$ and their health literacy ${ }^{72} 73$; as well as inadequate healthcare encounters. ${ }^{657273}$

A preliminary model describing how symptoms interact with BoT has been developed (see figure 5). Symptoms in CHF can erode patient agency through a complex interaction of symptoms decreasing capacity and increasing workload. This in turn leads to a loss of self-value and physical deconditioning, which together can inhibit a patients' ability to engage with self-care regimens due to perceived overwhelming BoT.

Current research on self-care in CHF focuses on the assumption of patient self-efficacy, which assumes given the right approach, intervention, and education a patient will have the capacity to engage in self-care regimens which will positively impact clinical outcomes. Recent revisions to the theory of self-care in CHF includes the consideration of symptom monitoring and management as a part of patients' self-care work. ${ }^{74}$ However, the theory of self-care in CHF has yet to examine how symptoms might impact on the patients' agency to perform selfcare. To the best of our knowledge, no empirical work has yet explored the observed interaction between symptoms, self-care engagement in CHF, and how that influences BoT.

\section{Strengths and weakness of the study}

Our review is the first to explore qualitative literature on patients' experiences of CHF with respect to the interactions of symptoms with BoT. It builds on the foundation of BoT theory ${ }^{15}$ with specific consideration for CHF patients. It characterises the types of symptom interaction with patient engagement in the context of BoT; which our PPI group recognised and verified as true to their experiences across multiple chronic illnesses.

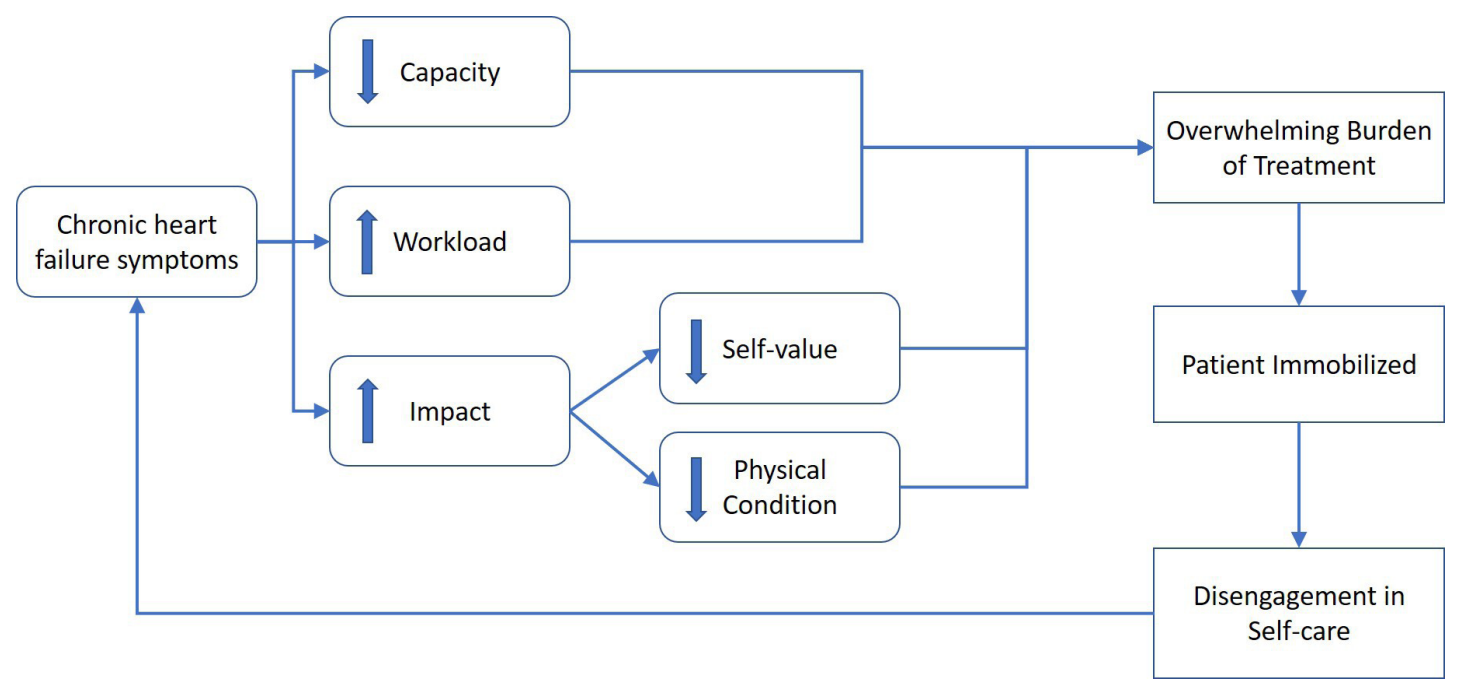

Figure 5 Initial model of CHF symptoms interaction with bot theory primary constructs. CHF, chronic heart failure. 
Using BoT as a framework was a strength, leading to the original observation of CHF symptoms forming a barrier to patient engagement with BoT and self-care. Hinting at the possibility of an alternative explanation for why healthcare professionals may perceive high levels of nonadherence in CHF patients.

A strength of the synthesis of qualitative research is that conclusions drawn were viewed through multiple theoretical, epistemological, and ontological stance of the included studies' authors as well as the authors of this review. Thus, commonalities observed are stronger due to heterogeneity of their context but could also be a limitation as the multiple interpretations may have altered the 'true' view of the original data. The review was restricted by the choice of published quotes from the included articles, our conclusions formed by using data from published primary studies to develop explanatory ideas the original researcher did not intend. Only English language articles were included.

Strengthening our analysis by using matrix queries, in Nvivo, to facilitate comparative pattern analysis as well as textual comparison, ${ }^{75}$ confirmed the patterns observed in the constant comparison process and provided the data to create visual illustrations of these complex interactions. Our coding analysis strategy, has precedent, as it was a refinement of Thomas and Harden ${ }^{23}$ methodology for thematic synthesis, which used a three stage coding process. We adapted their third stage to follow Gallacher et $a l^{14}$ work which takes second stage codes (characterise) and compares them against an a priori framework helping to explain the observations.

\section{Future work}

The role of symptoms in CHF and their interaction with patient engagement in self-care are not well understood and need more research. The authors are currently conducting empirical research to better understand this concept. ${ }^{76}$

\section{CONCLUSIONS AND CLINICAL IMPLICATIONS}

Our synthesis suggests that relying on patients' symptom experience as the impetus for them to seek healthcare support may not be as successful as currently assumed. Examination of symptom interaction with BoT in CHF has demonstrated a complex relationship. CHF symptoms appear to negatively interact with patients' engagement with self-care regimens, including healthcare interactions, through the creation of overwhelming BoT. Symptoms increase patients' illness workload simultaneously decreasing their capacity, with a detrimental impact on their lives. This interaction of symptoms suggests that patients with CHF may not be as poor at self-care as reported in current literature. CHF symptoms have an integral role in patient BoT predominately acting to impede patients' efforts to engage in self-care. Healthcare professionals need to carefully consider patients' capacity and current workloads when altering patient self-care regimens, as reducing workload may improve patient outcomes and improve engagement with self-care. The results of this review postulate that patients previously being blamed for poor self-care may be suffering from overwhelming BoT of which symptoms, which are modifiable are a major contributor. Our findings call for more research underpinned by BoT in CHF; exploring changes CHF service delivery and interventions to enhance patient self-care by focusing on their experiences.

\section{Author affiliations}

${ }^{1}$ Department of Cardiology, Portsmouth Hospitals University NHS Trust, Portsmouth, UK

${ }^{2}$ School of Health Sciences, Faculty of Environmental and Life Sciences, University of Southampton, Southampton, UK

${ }^{3}$ National Institite for Health Research (NIHR) Applied Research Collaboration (ARC) Wessex, Southampton, UK

${ }^{4}$ Julius Center for Health Sciences and Primary Care, University Medical Center Utrecht, Utrecht University, Utrecht, The Netherlands

${ }^{5}$ University Hospital Southampton NHS Foundation Trust, Southampton General Hospital, Southampton, UK

${ }^{6}$ Faculty of Health and Science, University of Portsmouth, Portsmouth, UK ${ }^{7}$ Institute of Health and Wellbeing, College of Medical, Veterinary and Life Sciences, University of Glasgow, Glasgow, Scotland

${ }^{8}$ Faculty of Public Health and Policy, London School of Hygiene and Tropical Medicine, London, UK

${ }^{9}$ National Institute for Health Research (NIHR), Applied Research Collaboration (ARC) North Thames, London, UK

Twitter Rosalynn C Austin @RosalynnAustin, Lisette Schoonhoven @। schoonhoven, Alison Richardson @AlisonProf and Carl R May @CarlRMay

Acknowledgements Paula Sands (PS), Health Sciences Librarian and Kate Lippiett $(\mathrm{KL})$ for their assistance with the creating and adapting the literature searches used in this review. Patient Research Ambassadors (PRA's) at Portsmouth Hospitals University NHS Trust for providing PPI in this review (Bill Ware, Anna GanvilleHearson, Graham Edwards, Noreen Cole, Jane Ward, Tim Coney, Darren Jenkinson). Mr Mark Green (MG), Heart Failure Specialist Nurse, whose clinical expertise assisted in the confirmation of the symptom codes used in this review.

Collaborators Patient Research Ambassadors (PRA's) at Portsmouth Hospitals University NHS Trust: Bill Ware, Anna Ganville-Hearson, Graham Edwards, Noreen Cole, Jane Ward, Tim Coney, Darren Jenkinson. Mark Green (MG), Heart Failure Specialist Nurse.

Contributors RA drafted this paper. RA, LS, and CRM developed the conceptual framework that informed this work. RA designed the review with support and guidance from CRM, LS, and PRK. RA assisted by CRM and LS performed the work of the literature searches. MC assisted in the screening of the articles and CRM and LS acted as the arbiter for any disputes. RA performed the first-line analysis and was guided by CRM, LS, and AR throughout constant comparison analysis. PRA and MG checked line-by-line symptom coding, refined the symptom coding structure and confirmed the results to be representative of their personal patient experiences. CRM, LS, AR and PRK critically reviewed the manuscript for intellectual and clinical content. All authors approved the final version of the paper. RA is the guarantor.

Funding This work was completed as a part of a fully funded Clinical Academic Doctoral Fellowship at the University of Southampton, Portsmouth Hospitals University NHS Trust, and the National Institute for Health Research (NIHR) Applied Research Collaboration (ARC) Wessex. This article is independent research funded in part by the NIHR ARC Wessex.

Disclaimer The views expressed in this publication are those of the author(s) and not necessarily those of the National Institute for Health Research, NHS or the Department of Health and Social Care.

Competing interests $A R$ is a National Institute for Health Research (NIHR) Senior Investigator. The views expressed in this publication are those of the author(s) and not necessarily those of the National Institute for Health Research, NHS or the Department of Health and Social Care.

Patient consent for publication Not required.

Provenance and peer review Not commissioned; externally peer reviewed. 
Data availability statement Data are available on reasonable request. Data presented in this work was taken from previously published articles.

Supplemental material This content has been supplied by the author(s). It has not been vetted by BMJ Publishing Group Limited (BMJ) and may not have been peer-reviewed. Any opinions or recommendations discussed are solely those of the author(s) and are not endorsed by BMJ. BMJ disclaims all liability and responsibility arising from any reliance placed on the content. Where the content includes any translated material, BMJ does not warrant the accuracy and reliability of the translations (including but not limited to local regulations, clinical guidelines, terminology, drug names and drug dosages), and is not responsible for any error and/or omissions arising from translation and adaptation or otherwise.

Open access This is an open access article distributed in accordance with the Creative Commons Attribution Non Commercial (CC BY-NC 4.0) license, which permits others to distribute, remix, adapt, build upon this work non-commercially, and license their derivative works on different terms, provided the original work is properly cited, appropriate credit is given, any changes made indicated, and the use is non-commercial. See: http://creativecommons.org/licenses/by-nc/4.0/.

\section{ORCID iDs}

Rosalynn C Austin http://orcid.org/0000-0001-8274-4836

Lisette Schoonhoven http://orcid.org/0000-0002-7129-3766

Mike Clancy http://orcid.org/0000-0001-8669-5226

Alison Richardson http://orcid.org/0000-0003-3127-5755

Paul R Kalra http://orcid.org/0000-0002-5288-3074

Carl R May http://orcid.org/0000-0002-0451-2690

\section{REFERENCES}

1 Conrad N, Judge A, Tran J, et al. Temporal trends and patterns in heart failure incidence: a population-based study of 4 million individuals. Lancet 2018;391:572-80.

2 Blinderman CD, Homel P, Billings JA, et al. Symptom distress and quality of life in patients with advanced congestive heart failure. $J$ Pain Symptom Manage 2008;35:594-603.

3 Lee CS, Gelow JM, Denfeld QE, et al. Physical and psychological symptom profiling and event-free survival in adults with moderate to advanced heart failure. J Cardiovasc Nurs 2014;29:315-23.

4 Lum HD, Carey EP, Fairclough D, et al. Burdensome physical and depressive symptoms predict heart Failure-Specific health status over one year. J Pain Symptom Manage 2016;51:963-70.

5 McMurray JJV, Adamopoulos S, Anker SD, et al. Esc guidelines for the diagnosis and treatment of acute and chronic heart failure 2012 : the task force for the diagnosis and treatment of acute and chronic heart failure 2012 of the European Society of cardiology. developed in collaboration with the heart failure association (HFA) of the ESC. Eur Heart J 2012;33:1787-847.

6 Toukhsati SR, Driscoll A, Hare DL. Patient Self-management in Chronic Heart Failure - Establishing Concordance Between Guidelines and Practice. Card Fail Rev 2015;1:128-31.

7 Cameron J, Worrall-Carter L, Page K, et al. Does cognitive impairment predict poor self-care in patients with heart failure? Eur $J$ Heart Fail 2010;12:508-15.

8 Boman K, Olofsson M, Bergman A-CR, et al. Anaemia, but not iron deficiency, is associated with clinical symptoms and quality of life in patients with severe heart failure and palliative home care: a substudy of the prefer trial. Eur J Intern Med 2017;46:35-40.

9 Kessing D, Denollet J, Widdershoven J, et al. Fatigue and selfcare in patients with chronic heart failure. Eur $\mathrm{J}$ Cardiovasc Nurs 2016;15:337-44.

10 Demain S, Gonçalves A-C, Areia C, et al. Living with, managing and minimising treatment burden in long term conditions: a systematic review of qualitative research. PLoS One 2015;10:e0125457.

11 Lippiett KA, Richardson A, Myall M, et al. Patients and informal caregivers' experiences of burden of treatment in lung cancer and chronic obstructive pulmonary disease (COPD): a systematic review and synthesis of qualitative research. BMJ Open 2019;9:e020515.

12 May CR, Eton DT, Boehmer K, et al. Rethinking the patient: using burden of treatment theory to understand the changing dynamics of illness. BMC Health Serv Res 2014;14:281.

13 Eton DT, Ramalho de Oliveira D, Egginton JS, et al. Building a measurement framework of burden of treatment in complex patients with chronic conditions: a qualitative study. Patient Relat Outcome Meas 2012;3:39-49

14 Gallacher K, Jani B, Morrison D, et al. Qualitative systematic reviews of treatment burden in stroke, heart failure and diabetes - methodological challenges and solutions. BMC Med Res Methodol 2013;13:10.

15 May CR, Cummings A, Myall M, et al. Experiences of long-term life-limiting conditions among patients and carers: what can we learn from a meta-review of systematic reviews of qualitative studies of chronic heart failure, chronic obstructive pulmonary disease and chronic kidney disease? BMJ Open 2016;6:e011694.

16 Shippee ND, Shah ND, May CR, et al. Cumulative complexity: a functional, patient-centered model of patient complexity can improve research and practice. J Clin Epidemiol 2012;65:1041-51.

17 Austin RC, Schoonhoven L, Kalra PR, et al. Burden of treatment in chronic heart failure: does symptom burden play a role? $\mathrm{Br} \mathrm{J}$ Card Nurs 2019;14:91-3.

18 Covidence systematic review [software] [program]. Melbourne, Australia. Available: www.covidence.org

19 Critical Appraisal Skills Programme. Casp qualitative research checklist. online, 2017.

20 NVivo Qualitative Data Analysis Software [Software] [program]:, 1999. Available: https://qsrinternational.com/nvivo/nvivo-products/

21 Hamad EO, Savundranayagam MY, Holmes JD, et al. Toward a mixed-methods research approach to content analysis in the digital age: the combined Content-Analysis model and its applications to health care Twitter feeds. J Med Internet Res 2016;18:e60.

22 SankeyMATIC [software] [program]. Available: http://sankeymatic. com/

23 Thomas J, Harden A. Methods for the thematic synthesis of qualitative research in systematic reviews. BMC Med Res Methodol 2008;8:45.

24 Glaser BG, Strauss A, Theory G. The discovery of Grounded theory: strategies for qualitative research. Chicago, IL: Aldine Publishing Co, 1967: 21-43.

25 Glaser BG. The constant comparative method of qualitative analysis. Soc Probl 1965;12:436-45.

26 Chiaranai C. A phenomenological study of day-to-day experiences of living with heart failure: do cultural differences matter? J Cardiovasc Nurs 2014;29:E9-17.

27 Gallacher K, May CR, Montori VM, et al. Understanding patients' experiences of treatment burden in chronic heart failure using normalization process theory. Ann Fam Med 2011;9:235-43.

28 Gowani A, Gul R, Dhakam S, et al. Living with heart failure: Karachi exploratory study. Br J Card Nurs 2017;12:586-92.

29 Walthall $\mathrm{H}$, Jenkinson C, Boulton M. Living with breathlessness in chronic heart failure: a qualitative study. $J$ Clin Nurs 2017;26:2036-44.

30 Kimani KN, Murray SA, Grant L. Multidimensional needs of patients living and dying with heart failure in Kenya: a serial interview study. BMC Palliat Care 2018;17:28

31 Falk S, Wahn A-K, Lidell E. Keeping the maintenance of daily life in spite of chronic heart failure. A qualitative study. Eur J Cardiovasc Nurs 2007;6:192-9.

32 Allen JW, Arslanian-Engoren C, Lynch-Sauer J. The lived experience of middle-aged women with new York heart association class III heart failure: a pilot study. Prog Cardiovasc Nurs 2009;24:96-101.

33 Attenburrow K. Live for the day with atrial fibrillation plus heart failure: Keith's story. Br J Card Nurs 2016;11:508-10.

34 Cortis JD, Williams A. Palliative and supportive needs of older adults with heart failure. Int Nurs Rev 2007;54:263-70.

35 Fry M, McLachlan S, Purdy S, et al. The implications of living with heart failure; the impact on everyday life, family support, co-morbidities and access to healthcare: a secondary qualitative analysis. BMC Fam Pract 2016;17:139.

36 Heo S, Moser DK, Lennie TA, et al. Patients' beliefs about causes and consequences of heart failure symptoms. West $J$ Nurs Res 2019;41:1623-41.

37 Holden RJ, Schubert CC, Mickelson RS. The patient work system: an analysis of self-care performance barriers among elderly heart failure patients and their informal caregivers. Appl Ergon 2015;47:133-50.

38 Mangolian Shahrbabaki P, Nouhi E, Kazemi M, et al. The sliding context of health: the challenges faced by patients with heart failure from the perspective of patients, healthcare providers and family members. J Clin Nurs 2017;26:3597-609.

39 Ming LC, Hassali MA, Shafie AA, et al. Perspectives of heart failure patients in Malaysia towards medications and disease state management: findings from a qualitative study. J Public Health 2011;19:569-77.

40 Moshki M, Khajavi A, Hashemizadeh $\mathrm{H}$, et al. Dark or bright half of the moon: a qualitative study exploring the experience of Iranian heart failure patients regarding their quality of life. Open Access Maced J Med Sci 2019;7:824-30. 
41 Paton B, Backlund J, Barnes M, et al. Recalibrating time and space: women's challenges of living with heart failure. Can J Cardiovasc Nurs 2007;17:7-14.

42 Paturzo M, Petruzzo A, Bertò L, et al. The lived experience of adults with heart failure: a phenomenological study. Ann Ig 2016;28:263-73.

43 Piamjariyakul U, Smith CE, Werkowitch M, et al. Part I: heart failure home management: patients, multidisciplinary health care professionals and family caregivers' perspectives. Appl Nurs Res 2012;25:239-45.

44 Retrum JH, Boggs J, Hersh A, et al. Patient-identified factors related to heart failure readmissions. Circ Cardiovasc Qual Outcomes 2013;6:171-7.

45 Ryan M, Farrelly M. Living with an unfixable heart: a qualitative study exploring the experience of living with advanced heart failure. Eur $J$ Cardiovasc Nurs 2009;8:223-31.

46 Sano M, Majima T. Self-Management of congestive heart failure among elderly men in Japan. Int J Nurs Pract 2018;24:e12653-1.

47 Tenner C. Everybody has a story, and I am lucky! JACC Heart Fail 2018;6:964-6.

48 Woda A, Haglund K, Belknap RA, et al. Self-Care behaviors of African Americans living with heart failure. J Community Health Nurs 2015;32:173-86.

49 Rerkluenrit J, Panpakdee O, Malathum P. Self-Care among Thai people with heart failure. Thai J Nurs Res 2009;13:43-53.

50 Nordfonn OK, Morken IM, Bru LE, et al. Patients' experience with heart failure treatment and self-care-A qualitative study exploring the burden of treatment. J Clin Nurs 2019;28:1782-93.

51 Walthall $\mathrm{H}$, Floegel T, Boulton $\mathrm{M}$, et al. Patients experience of fatigue in advanced heart failure. Contemp Nurse 2019;55:71-82.

52 Nordgren L, Asp M, Fagerberg I. Living with moderate-severe chronic heart failure as a middle-aged person. Qual Health Res 2007;17:4-13.

53 Pattenden JF, Roberts H, Lewin RJP. Living with heart failure; patient and carer perspectives. Eur J Cardiovasc Nurs 2007;6:273-9.

54 Andersson L, Eriksson I, Nordgren L. Living with heart failure without realising: a qualitative patient study. $\mathrm{Br} J$ Community Nurs 2012;17:630-7.

55 Mahoney-Davies G, Davis C, Glen C, et al. Examining the emotional and psychological experiences of people with heart failure. British Journal of Cardiac Nursing 2017;12:192-8.

56 Seah ACW, Tan KK, Huang Gan JC, et al. Experiences of patients living with heart failure: a descriptive qualitative study. J Transcult Nurs 2016;27:392-9.

57 Ahmad FS, Barg FK, Bowles KH, et al. Comparing perspectives of patients, caregivers, and clinicians on heart failure management. $J$ Card Fail 2016;22:210-7.

58 Slagle AF, Martin M. Hearing the voice of the heart failure patient: key experiences identified in qualitative interviews. Br J Cardiol 2012;19:25.

59 Hopp FP, Thornton N, Martin L, et al. Life disruption, life continuation: contrasting themes in the lives of African-American elders with advanced heart failure. Soc Work Health Care 2012;51:149-72.
60 Malhotra C, Cheng Sim Wong G, Tan BC, et al. Living with heart failure: perspectives of patients from Singapore. Proc Singapore Healthcare 2016;25:92-7.

61 Jani B, Blane D, Browne S, et al. Identifying treatment burden as an important concept for end of life care in those with advanced heart failure. Curr Opin Support Palliat Care 2013;7:3-7.

62 Seah ACW, Tan KK, Wang W. A narrative literature review of the experiences of patients living with heart failure. Holist Nurs Pract 2015;29:280-302.

63 Falk H, Ekman I, Anderson R, et al. Older patients' experiences of heart failure-an integrative literature review. J Nurs Scholarsh 2013;45:247-55.

64 Yu DSF, Lee DTF, Kwong ANT, et al. Living with chronic heart failure: a review of qualitative studies of older people. $J$ Adv Nurs 2008;61:474-83.

65 Olano-Lizarraga M, Oroviogoicoechea C, Errasti-Ibarrondo $\mathrm{B}$, et al. The personal experience of living with chronic heart failure: a qualitative meta-synthesis of the literature. J Clin Nurs 2016;25:2413-29.

66 Ivynian SE, DiGiacomo M, Newton PJ. Care-seeking decisions for worsening symptoms in heart failure: a qualitative metasynthesis. Heart Fail Rev 2015;20:655-71.

67 Evans MM. Symptom recognition and healthcare utilization in adult patients with heart failure: an integrative review of the literature. MEDSURG Nursing 2016;25:319-68.

68 Welstand J, Carson A, Rutherford P. Living with heart failure: an integrative review. Int J Nurs Stud 2009;46:1374-85.

69 Gallacher K, Morrison D, Jani B, et al. Uncovering treatment burden as a key concept for stroke care: a systematic review of qualitative research. PLoS Med 2013;10:e1001473.

70 Gonçalves A-CV, Jácome CIO, Demain SH, et al. Burden of treatment in the light of the international classification of functioning, disability and health: a "best fit" framework synthesis. Disabil Rehabil 2017;39:1-9.

71 Roberti J, Cummings A, Myall M, et al. Work of being an adult patient with chronic kidney disease: a systematic review of qualitative studies. BMJ Open 2018;8:e023507.

72 Jeon Y-H, Kraus SG, Jowsey T, et al. The experience of living with chronic heart failure: a narrative review of qualitative studies. BMC Health Serv Res 2010;10:77.

73 Rodriguez KL, Appelt CJ, Switzer GE, et al. "They diagnosed bad heart": a qualitative exploration of patients' knowledge about and experiences with heart failure. Heart Lung 2008;37:257-65.

74 Riegel B, Jaarsma T, Lee CS, et al. Integrating symptoms into the middle-range theory of self-care of chronic illness. ANS Adv Nurs Sci 2019;42:206-15.

75 Bazeley $\mathrm{P}$, Jackson K. Using coding queries to further analysis.. In: Qualitative data analysis with Nvivo. 2 edn. Sage, 2013: 242-69.

76 Austin RC, Schoonhoven L, Richardson A. How do SYMPtoms and management tasks in chronic heart failure imPACT a person's life (SYMPACT)? Protocol for a mixed-methods study. ESC Heart Fail 2020;17:4472-7. 